Transportation Research Forum

Estimating Cost Savings of Coordinating Regional Non-Emergency Human Transport Services Author(s): Ryoichi Sakano and Julian Benjamin

Source: Journal of the Transportation Research Forum, Vol. 46, No. 3 (Fall 2007), pp. 33-49

Published by: Transportation Research Forum

Stable URL: http://www.trforum.org/journal

The Transportation Research Forum, founded in 1958, is an independent, nonprofit organization of transportation professionals who conduct, use, and benefit from research. Its purpose is to provide an impartial meeting ground for carriers, shippers, government officials, consultants, university researchers, suppliers, and others seeking exchange of information and ideas related to both passenger and freight transportation. More information on the Transportation Research Forum can be found on the Web at www.trforum.org. 


\title{
Estimating Cost Savings of Coordinating Regional Non-Emergency Human Transport Services
}

\author{
by Ryoichi Sakano and Julian Benjamin
}

Local public transportation agencies provide a nonemergency human transport service to nearby hospitals and doctors' offices. Some users require specialized medical services at a hospital located out of the normal service area. In the Piedmont/Triad region of North Carolina, the Piedmont Authority for Regional Transportation (PART) began PART Connections in April 2004, to provide two daily transportation services between the Piedmont/Triad area and the UNC/Duke medical areas.

Using current operating cost data of participating transportation systems, round-trip costs to the UNC/Duke medical areas from each county and to the nearest PART Connections stop are estimated. Given the actual number of passengers served by PART Connections during the first ninemonth period of the service, the net saving in the operating cost by participating PART Connections is estimated for each system. Then, the total service hours saved by using PART Connections are estimated for each system, and are used to estimate the number of additional passengers served within the system.

It is estimated that PART Connections could provide a net saving of $\$ 38,000$ on operation expenses annually to the participating four county transportation systems. More importantly, PART Connections would enable the four county systems to provide more than 10,000 additional passenger trips within each county annually, by using the saved resources. In addition, 12 local community transportation providers in 15 western counties of the Piedmont/Triad region, which currently do not participate in PART Connections, are estimated to save a modest $\$ 9,600$ in total annually, by using PART Connections.

\section{BACKGROUND, SCOPE AND OBJECTIVE}

Community transportation agencies give access to employment, health care, and other services for persons with limited mobility due to age and disabilities. To meet transportation needs, a variety of transportation programs have been created and provided through local agencies. However, these services are fragmented, and some public transportation resources are not used efficiently and effectively. Recognizing this problem, the White House issued an executive order for "the development, implementation, and maintenance of responsive, comprehensive, coordinated community transportation systems" (White House 2004).

Throughout North Carolina, local transportation authorities provide human service transportation in which a local transportation authority works with local human service agencies to transport qualified residents for medical, educational, employment, or recreational needs. Currently, there are 55 human service transportation systems in the state. In addition, the community transit systems provide transportation for human service agency clients (North Carolina Department of Transportation 2003).

The North Carolina Department of Transportation (NCDOT) initiated a pilot program in 1997 to coordinate the nonemergency medical transportation in the 27 eastern Carolina counties. An administrator at the East Carolina Medical Center in Greenville coordinates the medical appointments and transportation schedules of clients. The coordination resulted in a $25 \%$ reduction in missed medical appointments during the two-year project, but no cost reduction in transportation services was observed (Hawley et al. 2003). In 1999, the NCDOT started another pilot program in 
18 western Carolina counties. Specialized medical care to residents in these counties is provided at Mission-St. Joseph's Health System in Ashville, where a coordinator residing at the hospital coordinates both medical appointment schedules and transportation schedules among local transit authorities. During a three-month study period in 1999, five participating counties saved $\$ 1,917$ by reducing the number of trips (Rhoney et al. 2001).

In 2002, the Piedmont/Triad region of North Carolina was selected for the third pilot program. The region includes 18 counties (Alexander, Alleghany, Ashe, Caldwell, Catawba, Davidson, Davie, Forsyth, Guilford, Iredell, Randolph, Rockingham, Rowan, Stokes, Surry, Watauga, Wilkes, and Yadkin), including the Greensboro-Winston-Salem-High Point metropolitan area. This pilot program is distinguished from the two previous programs in several ways. First, the Piedmont Authority for Regional Transportation (PART) is responsible for coordination (i.e. pooling the transportation resources and activities of several human service agencies with each other or with mass transit operations, Burkhardt et al. 2003) of out-of-county transportation services (Piedmont Authority for Regional Transportation 2002). Second, three major cities in the region already had established well-functioning paratransit services within each city and county limit. Third, there are four major specialized hospitals in the region with different specialties (Moses Cone Hospital in Greensboro, Baptist Hospital and Forsyth Medical Center in Winston-Salem, and High Point Regional Hospital in High Point). In addition, there are many medical transportation trips to University of North Carolina (UNC) Hospital in Chapel Hill and Duke Hospital in Durham.

In the Piedmont/Triad region, diverse medical care providers and corridor networks call for two distinguished out-of-county transport services, each of which requires a unique coordination effort, one for an intraregional transport service (i.e. transport across 18 counties within the Piedmont/ Triad region) and another for an interregional transport service (i.e. transport between the Piedmont/ Triad region and other regions in North Carolina). Because many hospitals are located within the region, the intraregional transport service is difficult to coordinate among counties. In contrast, it is easier to accumulate ridership along the highway, and coordinate trips among counties to the UNC and Duke medical areas for the interregional transport service. The previous pilot programs coordinated intraregional transport services. However, in this study the focus is on the interregional transport service coordination, called PART Connections. PART Connections provides a fixed route service between Forsyth, Guilford, and Alamance counties, and the UNC and Duke medical areas.

Coordinating paratransit has been shown to have economic benefits throughout the country (Burkhardt et al. 2003). These benefits can be achieved by shifting riders from paratransit services to fixed route services, and coordinating transit programs. While an immediate economic benefit is the cost saving through more efficient operation, a perhaps more significant impact is to increase mobility by expanding services. PART Connections simultaneously provided all of these benefits. The objectives of this paper are to develop a procedure to measure the economic benefits of out-ofcounty transportation coordination, and to evaluate the economic benefits of PART Connections in the Piedmont/Triad region.

To this date, various manuals for planning and implementing coordination, and a number of coordination implementation plans have been provided by governments, trade groups, consultants, and practitioners. However, studies of actual applications, in particular by academics, provide a procedure to measure the economic effects of coordination. This paper proposes a systematic procedure to estimate cost savings from coordinating and consolidating transport services provided by multiple service providers, and to measure the economic benefit in terms of service expansion. It is shown that all of these estimates can be made by using existing transit operation data, which are readily available for most transit systems in the United States. The proposed methods are applied to PART Connections, a coordinated nonemergency human transport service in North Carolina, to estimate the economic effects of the coordination of 15 transit systems in 18 counties in the Piedmont/Triad region and Alamance County transit system. Thus, the proposed procedure will provide local transit system operators and regional/state transportation planners a tool to evaluate 
the coordination and consolidation of out-of-county transportation services, and to estimate potential benefits from its implementation.

\section{LITERATURE REVIEW OF TRANSIT COORDINATION}

One way to transport clients who cannot drive to hospitals for medical treatment has been to provide coordinated travel. Instead of individual trips, the coordinated service transports people with different destinations and different funding sources together in centrally dispatched vehicles. The economic advantages of this approach for any community were outlined in Murray et al. (1999).

Many public transit systems throughout the United States have been implementing regional and statewide transit coordination as a means of improving their services through more effective and efficient transportation services. A number of studies have been done to review those practices in recent years. Rubel et al. (2002) reviewed many statewide coordination practices and identified "the benefits of transportation coordination." The expected benefits of effective coordination among providers and agencies include an elimination of duplicated services and an improvement in the cost-effectiveness of the transportation service among others. The study also reported current statewide coordination efforts in nine states.

In 2003, the Committee on Education and the Workforce, and the Committee on Transportation and Infrastructure in the U.S. House of Representatives, had a joint Congressional hearing on coordinating human services transportation (House Committee on Education and the Workforce 2003). Later, the Transit Cooperative Research Program, sponsored by the Federal Transit Administration,conducted a review of the economic benefits of coordinating human service transportation and transit services (Burkhardt et al. 2003). The report found five areas of major economic benefits of coordinating human service transportation and regular fixed route transit services. The report estimated the economic benefits of successful coordination of human service transportation and transit services to be $\$ 700$ million per year in total in the United States. The report also presented many cases of successful coordination efforts throughout the country, with estimated economic impacts. For example, in King County, Washington, the Department of Social and Health Services (DSHS) coordinated ADA and Medicaid transportation through brokerage, and reported a benefit of $\$ 101,000$ from 1998 to 1999 . However, the examples and concepts provided by Burkhardt et al. (2003) are, for the most part, limited to services inside one municipality or county. Burkhardt (2005) further reviewed several rural coordination projects which were also limited to local communities.

Burkhardt's studies listed several economic benefits, and estimated savings from coordination. Murray et al. (1999) used unit trip costs to estimate the operating cost of each transportation service, and compared the cost of operating the service to alternative coordinated services.

Transportation is an important issue in rural areas because of the inefficiency in operation due to low density population and wide service areas. Hegland et al. (2004) reviewed the current coordination efforts in the rural western part of North Dakota, and recommended the establishment of regional coordinating councils in an effort to reduce duplication of services. One challenge in coordinating rural paratransit services is to create efficient and effective routes on a daily basis. McGrane et al. (2004) surveyed small- to medium-size rural paratransit agencies, and identified factors in administrative infrastructure necessary to provide efficient rural paratransit schedules and services. Burkhardt et al. (2004) reviewed coordination practices used in various rural transportation systems and proposed a strategy to implement a successful coordination plan in rural communities. As in earlier nationwide studies by the same author, this study described in detail the savings that accrue as the result of coordinating a variety of different rural transportation services. While they reviewed a large variety of paratransit services, none of the cases involved a region-wide, out-ofcounty transportation service to health care destinations outside of the region.

To this date, there has been only one cost study of coordination of out-of-county human service transportation in North Carolina. Rhoney and Pratt (2001) and Rhoney et al. (2001) studied the 
coordination among five western Carolina counties with Mission-St. Joseph's Health System in Ashville in 1999. They reviewed out-of-county nonemergency medical trip logs and transportation logs to identify actual coordinated trips and operating costs in the five participating counties over a three-month period. They estimated $\$ 1,917$ in savings from coordination (coordinated trip mileages $\mathrm{x}$ operating cost per mile) in a three-month period, or $\$ 7,668$ annually. With further coordination, the study estimated that these five participating counties would potentially save $\$ 68,400$ annually.

This paper distinguishes itself from the previous studies in transportation coordination, by addressing the coordinated interregional human service transport, and proposing a systematic procedure to estimate cost savings from coordination, and to measure its economic benefit in terms of service expansion from saved resources from coordination.

\section{MULTICOUNTY REGIONAL TRANSIT SYSTEMS IN NORTH CAROLINAAND IN THE PIEDMONT/TRIAD REGION}

Paratransit service providers exist in 85 counties in North Carolina, and coordination among those providers is essential. The Public Transportation Division of the Department of Transportation started considering the idea of coordinating the out-of-county, nonemergency medical transportation in 1994. Hawley et al. (2003) presented a statewide coordination plan in which the entire state is divided into six regions in terms of geographical location and highway network, proximity to major medical facilities, and out-of-county paratransit service needs (i.e. a paratransit service that requires a transit system to drive outside its county boundaries to take passengers to their destination). "Coordination" of out-of-county, nonemergency medical transportation "is the result of community transportation systems along highway corridors working together in common effort to create enhanced services for passengers and realizing operating efficiencies through communication, shared resources and working partnerships" (Hawley et al. 2003). Cook (2002) reviewed the current practice of regional public transportation services in North Carolina, including the Piedmont Authority for Regional Transportation (PART) in the Piedmont/Triad region. He identified a number of economic benefits, including coordination and consolidation with human service agency transportation, and recommended establishment of regional coordinators and a uniform human service transportation procedure.

Figure 1: Out-of-County Transportation in Piedmont/Triad Region and Alamance County

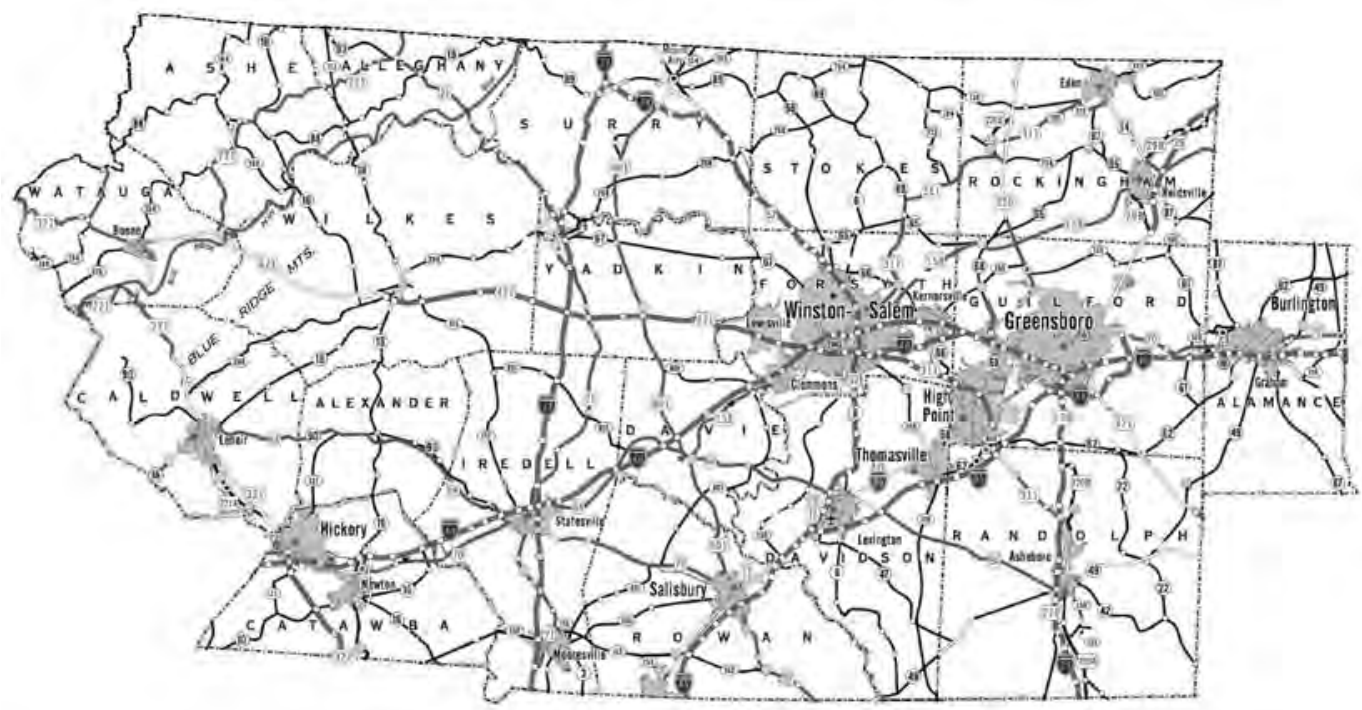


In the Piedmont/Triad region of North Carolina, patients in the 18 counties in the region who need special medical care may travel to the major medical center located in Winston-Salem, Forsyth County. The major highways in the region are Interstate 85 and 40, and US 29, 52, 158, 311, and 421 (Figure 1). In the Piedmont/Triad region, PART integrates the transportation services in the metropolitan area of Forsyth and Guilford County, as well as the surrounding five counties (Alamance, Davidson, Randolph, Rockingham, and Surry). Note that Alamance County is not one of 18 counties in the Piedmont/Triad region. PART currently provides an intercity express transit service between three cities, as well as an airport business park. Local bus services are provided at each urban center and in the surrounding areas, and are currently operated independently by the local DOT (Greensboro, High Point, and Winston-Salem). The center of each of the three cities serves as a hub for buses on many fixed routes to surrounding commercial and residential areas, and provides a connection to the intercity express transit service. Also, each DOT independently operates demand-response transportation services to city residents, as well as county-wide.

PART provides the nonemergency human service transportation for residents who need transportation to medical appointments outside their home county, called "PART Connections." On April 5, 2004, PART started daily transportation services from Winston-Salem to the UNC-Chapel Hill and Duke Medical areas (80 miles east from Winston-Salem) for Guilford and Forsyth County clients in the Piedmont/Triad region, as well as for Alamance County clients (in Northern Capital region) who are picked up along the way (Figure 2).

Figure 2: PART Connections Route and Schedule

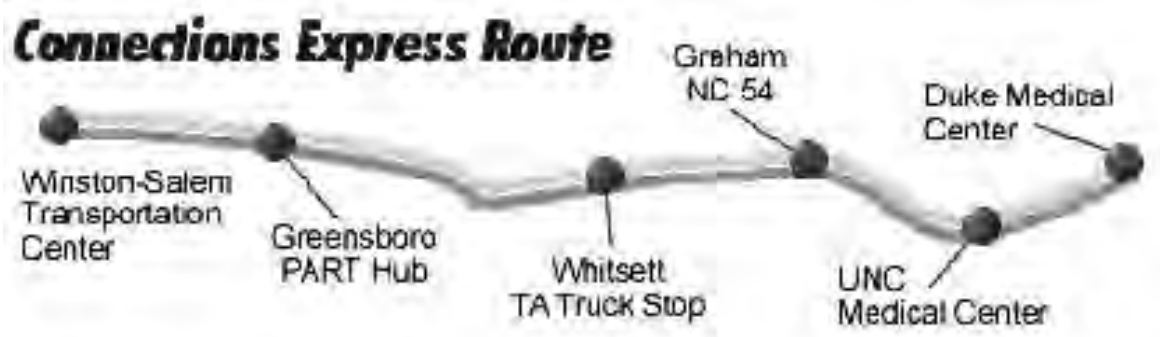

DAILY SCHEDULE

\begin{tabular}{lrlr}
\multicolumn{1}{c}{ AM Route } & \multicolumn{2}{c}{ PM Route } \\
W-S Transportation Ctr. & $6: 30 \mathrm{am}$ & W-S Transportation Ctr. & $11: 30 \mathrm{am}$ \\
PART Hub & $7: 00 \mathrm{am}$ & PART Hub & $12: 00 \mathrm{pm}$ \\
TA Truck Stop & $7: 30 \mathrm{am}$ & TA Truck Stop & $12: 30 \mathrm{pm}$ \\
NC 54 & $7: 45 \mathrm{am}$ & NC 54 & $1: 00 \mathrm{pm}$ \\
UNC Hospital & $8: 30 \mathrm{am}$ & UNC Hospital & $1: 30 \mathrm{pm}$ \\
Duke Hospital & $9: 10 \mathrm{am}$ & Duke Hospital & $2: 10 \mathrm{pm}$ \\
\multicolumn{1}{r}{ AM Route (Returns) } & $11: 45 \mathrm{am}$ & Duke Hospital PM Route (Returns) & $4: 15 \mathrm{pm}$ \\
Duke Hospital & $12: 15 \mathrm{pm}$ & UNC Hospital & $5: 05 \mathrm{pm}$ \\
UNC Hospital & $12: 40 \mathrm{pm}$ & NC 54 & $5: 30 \mathrm{pm}$ \\
NC 54 & $1: 00 \mathrm{pm}$ & TA Truck Stop & $5: 50 \mathrm{pm}$ \\
TA Truck Stop & $1: 30 \mathrm{pm}$ & PART Hub & $6: 30 \mathrm{pm}$ \\
PART Hub & $2: 00 \mathrm{pm}$ & W-S Transportation Ctr. & $7: 00 \mathrm{pm}$ \\
W-S Transportation Ctr. & & &
\end{tabular}

Source: PART website (http://www.partnc.org) 


\section{DATA AND METHODOLOGY}

The study method is to estimate costs of traveling directly, or by the fixed route, based on available data.

\section{Data}

The following data is used for analyzing coordination of out-of-county transport operation.

PART Connections Operation Data. PART provided PART Connections operation data for the nine-month period between its inception in April 2004, and December 2004. It includes the daily passenger counts on PART Connections by destination, passenger type, route, and the county of origination.

Out-of-County Trip Survey Data. The out-of-county paratransit operation survey form was distributed in November 2004 to all 15 systems in the 18 counties in the Piedmont/Triad region and the Alamance County system. Four county systems responded and provided the out-of-county operation data for the fiscal year of 2003-4.

Past Out-of-County Trip Data. PART collected out-of-county operation information from drivers' manifests of five county systems for a six-month period during the fiscal year of 2002. The data includes the daily passenger counts by destination.

Operating and Financial Statistics Report (OPSTATS). The financial and the overall operation information of each system were obtained from the OPSTATS, collected by the NCDOT for the fiscal year 2004. OPSTATS provides the annual data of operation (service miles, service hours, passenger trips) and expenses by categories (driver, fuel/oil, maintenance, etc.).

Distance and Travel Time Information. MAPQUEST was used to obtain distance and travel time information; (a) between each county and the UNC medical area in Chapel Hill or the Duke medical area in Durham, and (b) between each county and the nearest PART Connections stop.

\section{Cost and Resource Saving Estimation Method}

Unit Travel Cost Estimate. Round-trip costs to the UNC/Duke medical areas from each county, and to the nearest PART Connections stop, are estimated from the OPSTATS data. Because the use of PART Connections will not eliminate administrative work, only operating expenses are included in the calculation of travel cost saving. Some operating expenses in the OPSTATS depend on hours of services such as driver costs, while others depend on travel distance such as fuel. Four different estimates of costs are made. Cost estimate No. 1 assumes that all costs depend on the travel time. First, an average operating expense per hour is computed as the ratio of the total operating expenses to the total service hours of the system. Next, assuming two-hour appointments (e.g. p.m. route of PART Connections provides two hours and five minutes between arrival and departure at the Duke medical area), the total service time is estimated as the sum of the travel time of a round trip to the UNC medical area and a two-hour waiting time. Then, the unit travel cost is computed as a product of the average operating expense per hour, and the total service time (Equation 1). Cost estimate No. 2 assumes that all costs depend on the travel distance. First, an average operating expense per mile is computed as a ratio of total operating expenses to total service miles of the system. Then, the unit travel cost is computed as a product of the average operating expense per mile and the total travel distance of a round trip to the UNC medical area (Equation 2). 
(1) Unit Travel Cost Based on Travel Time

$=[($ Operation Costs $) /($ Service Hours $)] \times[($ Travel Time $) \times 2+2$ hours $]$

(2) Unit Travel Cost Based on Travel Distance

$=[($ Operation Costs $) /($ Service Miles $)] \times[($ Travel Miles $) \times 2]$

In Equation (1) and (2), "Operation Costs" are the sum of "Driver," "Fuel/Oil," and "Vehicle Maintenance" costs of each system in 2004. "Service Hours" and "Service Miles" are the total service hours and total service miles of each system in 2004, respectively. "Travel Time" and "Travel Miles" are the number of hours and miles to travel from the nearest PART Connections stop (from each county) to the UNC medical area, respectively.

Cost estimates No. 3 and No. 4 assume that driver costs depend on the service time, while the fuel and maintenance operating expenses depend on the travel distance. For other operating expenses, cost estimate No. 3 assumes that all other operating expenses depend on travel time, while cost estimate No. 4 assumes that all other operating expenses depend on travel distance.

Total Travel Cost Estimate. Each system may arrange to transport passengers to the UNC/Duke medical areas in different ways, depending on how often the trip is made, and how many passengers are on each trip. Three possible scheduling arrangements are considered for the total travel cost estimate. Schedule No. 1 provides a trip to each passenger (possibly with attendants) every time a trip is requested. The total travel cost is computed as a product of the total number of trips, and the unit travel cost. Schedule No. 2 provides one daily trip to the UNC or Duke medical area. All passengers in the system travel to the hub in the county, and then share a vehicle to the UNC or Duke medical area. Later on the same day, the same vehicle provides a return trip to the county from the medical area. Schedule No. 3 provides two daily trips to the Duke medical area via the UNC medical area. This schedule is comparable to PART Connections.

Gross Operating Cost Saving Estimate. PART Connections has four stops in three counties (Forsyth, Guilford, and Alamance) along the way to the UNC/Duke medical areas. Except for these three county systems, when a county system utilizes PART Connections, it still must provide rides to passengers from its home county to the nearest PART Connections stop. The total costs of traveling from each county to the nearest PART Connections stop are computed in the same manner as the total costs of traveling to the UNC medical area. The total service time of a round rip to the nearest PART Connections stop is the sum of round-trip time from the county to the PART Connections stop, and an assumed 15 minutes waiting-and-transfer time at the stop. For most counties, it is feasible to make another round trip to pick up passengers later on the same day, instead of waiting at the stop. Therefore, the gross operating cost saving of using PART Connections is computed as a difference between the total travel cost to the UNC/Duke medical areas, and twice the total travel cost to the nearest PART Connections stop, assuming a county system makes two round trips to the stop.

Estimation Procedure of Additional Passengers. Use of PART Connections frees up some resources. The saved resources could be utilized to provide transportation services to other passengers within the county. An average passengers per hour is computed from the total number of passengers divided by the total service hours, then is multiplied by the total service hours saved by using PART Connections, to obtain an estimate of the number of additional passengers served within the system.

Econometric Model of Passenger Trips. For those counties without out-of-county transportation data, a statistical method was used to estimate their annual passenger trips to the UNC/Duke medical areas.

Gravity Model of Passenger Trips. The number of passengers traveling to hospitals in other counties depends on many factors, such as population in the county, needs for special medical care, 
levels of health care received from hospitals in the county and in other counties, and travel distance and time to hospitals in other counties relative to one in the county. Due to a limited number of observations and lack of data, a regression model is estimated only with a travel time between a patient's home county and a hospital in another county, and is shown below:

$$
\log (\mathrm{N} / \mathrm{P})=\alpha+\beta \times \log \left(\mathrm{D}^{2}\right)+\varepsilon
$$

where $\mathrm{N} / \mathrm{P}$ is a ratio of the annual number of passengers traveling to an out-of-county hospital to the population of the county, $\mathrm{D}$ is the travel time between the county and the out-of-county hospital, $\varepsilon$ is a random error which captures all other factors that affect the number of passengers, and $\alpha$ and $\beta$ are regression coefficients. Travel time rather than travel distance was used in place of $\mathrm{D}$ to estimate the model, because most passengers do not pay a fare for transport (which is paid through various programs), so they are only concerned with travel time. The number of passengers is assumed to decrease with the travel time, because they become increasingly reluctant to travel a greater distance. The out-of-county passenger travel data is used to estimate the model in equation (3).

Estimates of Passenger Trips. Using the estimated gravity model, the travel time and county population data are used to estimate an annual number of passengers traveling to an out-of-county hospital. By inserting information of $\mathrm{D}$ and $\mathrm{P}$ in the equation with estimated coefficients, $\alpha$ and $\beta$, the number of passengers $(\mathrm{N})$ can be obtained.

\section{COST ANALYSIS OF PART CONNECTIONS}

\section{Current Service of PART Connections}

PART Connections started its service in April 2004. Between April and December 2004, riders came from three counties in the Piedmont/Triad region (Davidson, Forsyth, and Guilford) and Alamance County. For the nine-month period, PART Connections provided services to 4,232 passengers with averages of 470 passengers per month and 21.8 passengers a day. About three-quarters of all passengers were from Alamance County $(3,149)$, and another one-quarter were from Guilford County (1,016). Passengers from Forsyth County (66) account for less than 2 percent of total passengers, and there was only one passenger from Davidson County. Of 4,232 passengers, 3,592 ambulant passengers (84.9\%), who had appointments in either the UNC medical area or the Duke medical area, were accompanied by 640 attendants. By destinations, there were 3.1 passengers per day to the UNC medical area and 2.1 passengers per day to the Duke medical area from Guilford County, and 14.2 passengers per day to the UNC medical area and 2.0 passengers per day to the Duke medical area from Alamance County.

\section{Cost Saving of Using PART Connections}

Unit Travel Cost Estimation. Unit travel costs (per vehicle round trip) to the UNC medical area from each county are computed by four different methods. The four cost estimates, and the median cost of the four, are presented in Table 1 (hereafter, only median cost estimates will be reported). The unit travel costs to the Duke medical area from the four counties are almost identical to the unit travel costs to the UNC medical area shown in Table 1, since both travel distance and time to the Duke medical area are not much different from those to the UNC medical area, respectively (one extra mile of travel, but three minutes less travel time, for all four counties).

PART Connections runs from Winston-Salem (Forsyth County) through Greensboro (Guilford County) and Burlington (Alamance County). The three counties only need to take passengers from their homes to a PART Connections stop in the county, often at or near the county transportation hub. Therefore, these three county systems would save entire (unit) travel costs to the UNC or 
Duke medical area (Table 1) if they used PART Connections, excluding the fee charged by PART for its services. However, passengers in Davidson County must be transported first to the nearest PART Connections stop. Out of the four stops, the Winston-Salem stop is the closest from Davidson County, based on the travel distance and time, so the unit round-trip travel cost to the Winston-Salem stop from Davidson County (City of Lexington as the origin of the trip for approximation) was computed. Then, the difference between the unit travel cost to the UNC medical area, and double the unit travel cost to the nearest PART Connections stop (two round trips to the stop) is the unit cost saving of using PART Connections, shown in the eighth row of Table $1(\$ 73.58=\$ 146.02-\$ 36.22$ x 2 for Davidson County). This is a gross saving that the Davidson County system may have, if it transports passengers to the nearest PART Connections stop and lets them use PART Connections, rather than transporting them to the UNC/Duke medical areas by itself.

Table 1: Unit Travel Cost of a Round Trip to UNC-Chapel Hill Hospital and Number of Passengers Served by PART Connections From April 2004 to December 2004

\begin{tabular}{|c|c|c|c|c|}
\hline & Guilford & Alamance & Forsyth & Davidson \\
\hline $\begin{array}{l}\text { Median Unit Travel Cost of Round Trip to } \\
\text { the UNC Medical Area }\end{array}$ & $\$ 131.70$ & $\$ 64.84$ & $\$ 190.20$ & $\$ 146.02$ \\
\hline Cost Estimate \#1 & $\$ 109.51$ & $\$ 59.91$ & $\$ 133.64$ & $\$ 100.40$ \\
\hline Cost Estimate \#2 & $\$ 153.29$ & $\$ 81.35$ & $\$ 245.26$ & $\$ 266.22$ \\
\hline Cost Estimate \#3 & $\$ 110.10$ & $\$ 63.98$ & $\$ 135.14$ & $\$ 134.72$ \\
\hline Cost Estimate \#4 & $\$ 153.29$ & $\$ 65.69$ & $\$ 245.26$ & $\$ 157.32$ \\
\hline $\begin{array}{l}\text { Median Unit Travel Cost of Round Trip to } \\
\text { the Nearest PART Connections Stop }\end{array}$ & --- & --- & --- & $\$ 36.22$ \\
\hline $\begin{array}{l}\text { Median Unit Cost Saving of Using PART } \\
\text { Connections }\end{array}$ & $\$ 131.70$ & $\$ 64.84$ & $\$ 190.20$ & $\$ 73.58$ \\
\hline Number of Passengers & 1,016 & 3,149 & 66 & 1 \\
\hline Ambulant Passengers & 862 & 2,673 & 56 & 1 \\
\hline
\end{tabular}

\section{Three Trip Schedules and Gross Operating Cost Saving of Using PART Connections}

The gross operating cost saving for the nine-month period for each county is computed under three alternative trip schedules and presented in Table 2. Schedule No. 1 assumes that each system provides a separate trip to each ambulant passenger (no separate trip for accompanying attendants), so the gross operating cost savings are products of "median unit cost saving of using PART Connections" and "ambulant passengers," shown in Table 1. Schedule No. 2 assumes that each system provides a daily round trip. This schedule is most efficient if there are several passengers each day to either the UNC medical area or the Duke medical area. The gross operating cost savings are "median unit cost saving of using PART Connections" in Table 1 times 194 service days (nine-month period). Schedule No. 3 provides two daily trips to the Duke medial area through the UNC medical area (like PART Connections). This schedule is suitable to systems that have passengers to both destinations every day. This schedule requires longer trips (an extra 11 miles and 19 minutes) than those used in the estimation of "median unit cost saving of using PART Connections" in Table 1, and resulted in higher estimates of median unit travel costs and corresponding savings ( $\$ 157.48$ for Guilford County and $\$ 79.34$ for Alamance County). The gross operating cost savings are computed for Guilford County and Alamance County as the revised median unit cost saving estimates $(\$ 157.48$ and $\$ 79.34$, respectively), times 194 (service days), times two (for two daily round trips). 
Non-Emergency Human Transport Services

Table 2: Gross Operating Cost Saving Estimates of Three Alternative Trip Schedules

\begin{tabular}{|l|c|c|c|c|}
\hline & Guilford & Alamance & Forsyth & Davidson \\
\hline Schedule \#1 & $\$ 113,525$ & $\$ 173,317$ & $\$ 10,651$ & $\$ 74$ \\
\hline Schedule \#2 & $\$ 25,549$ & $\$ 12,578$ & $\$ 36,899$ & ---- \\
\hline Schedule \#3 & $\$ 61,103$ & $\$ 30,784$ & ---- & ---- \\
\hline
\end{tabular}

\section{Gross Operating Cost Saving of Using PART Connections}

If these four counties did not use PART Connections, each system would have to provide its own transportation services to the UNC/Duke medical areas. During the nine-month period, Davidson County and Forsyth County had less than one passenger a day, so the most cost efficient alternative to PART Connections is to provide transport services to passengers on demand (Schedule No. 1). On the other hand, because there were at least two passengers each day to both the UNC and Duke medical areas, Alamance and Guilford County should provide two regular daily round trips to the Duke medical area through the UNC medical area (Schedule No. 3) equivalent to PART Connections, without lowering service levels. This schedule is more cost-efficient than Schedule No. 1 for these two county systems. Note that if these systems choose to provide more than two round trips to the UNC/Duke medical areas each day, then the gross cost saving by using PART Connections will be even greater.

Compared with the costs associated with these alternatives, the gross operating cost savings of using PART Connections for the nine-month period were $\$ 61,103$ for Guilford County (Schedule No. 3), \$30,784 for Alamance County (Schedule No. 3), \$10,651 for Forsyth County (Schedule No. 1), and $\$ 74$ for Davidson County (Schedule No. 1), and the combined total savings of the four counties amounts to $\$ 102,612$. This saving comes from pooling passengers from four counties into one transport service, rather than providing four separate services. It is important to mention that these cost savings can be achieved without lowering service quality, or imposing inconvenience to passengers, because the cost estimate is based on the assumption that PART Connections provides the equivalent trip schedule to the separate services provided by each county system.

Based on the nine-month period of operation, the four counties could save annually $\$ 136,816$ $(\$ 102,612 / 9 \times 12)$ of gross operating expenses by using PART Connections for passengers traveling to the UNC/Duke medical areas $(\$ 41,045$ for Alamance, $\$ 98$ for Davidson, $\$ 14,202$ for Forsyth, and $\$ 81,471$ for Guilford).

\section{Cost Analysis of PART Connections for Nonparticipating Counties}

In the Piedmont/Triad region, there are 12 transit systems in 15 counties which provide out-of-county, nonemergency human transport services, but have not yet participated in PART Connections.

\section{Four Counties with Trip Data}

Out-of-county travel data of two counties were obtained through a mail survey, and another two counties from drivers' manifest data collected earlier. The annual number of passengers to the UNC/Duke medical areas is presented in Table 3. The numbers of ambulant passengers are, then, estimated by multiplying the annual number of passengers by 0.84 (assuming a $16 \%$ of riders are attendants, accompanying ambulant passengers, who do not need separate trips - a number similar to current PART Connections operation). The table also presents unit travel cost estimates to the UNC/Duke medical areas and the nearest PART Connections stop, and unit cost saving and annual gross operating cost saving estimates if these four counties use PART Connections. Because each county has less than one passenger a day to the UNC/Duke medical areas, each system currently provides an on-demand transportation service (Schedule No. 1). 
Except for Randolph County, the gross operating cost savings of using PART Connections will not be much. Watauga County, which is located at the western end of the Piedmont/Triad region, seems not to have any cost saving. However, if a vehicle from Watauga County waits for a passenger at the PART Connections stop in Winston-Salem, rather than making two round trips, the Watauga County system will save $\$ 70.08$ on fuel and maintenance costs by not driving 152 miles (round trip) between Winston-Salem and the UNC/Duke medical areas.

\section{Table 3: Number of Trips to the UNC/Duke Medical Areas and Cost Saving Estimates} for Four Nonparticipating Counties

\begin{tabular}{|l|c|c|c|c|}
\hline & Randolph & Rockingham & Rowan & Watauga \\
\hline \begin{tabular}{l} 
Total Number of Passengers Per Year \\
\hline Ambulant Passengers
\end{tabular} & 266 & 42 & 4 & 18 \\
\hline $\begin{array}{l}\text { Unit Travel Cost of Round Trip to } \\
\text { UNC-CH or Duke }\end{array}$ & $\$ 121.68$ & $\$ 95.37$ & $\$ 52.55$ & $\$ 423.72$ \\
\hline $\begin{array}{l}\text { Unit Travel Cost of Round Trip to the } \\
\text { Nearest PART Connections Stop }\end{array}$ & $\$ 45.77$ & $\$ 44.84$ & $\$ 19.19$ & $\$ 218.35$ \\
\hline $\begin{array}{l}\text { Unit Cost Saving of Using PART } \\
\text { Connections Service }\end{array}$ & $\$ 30.14$ & $\$ 5.69$ & $\$ 14.17$ & $-\$ 12.98$ \\
\hline Annual Gross Operating Cost Saving & $\$ 6,690$ & $\$ 199$ & $\$ 57$ & $-\$ 195$ \\
\hline
\end{tabular}

\section{Eleven Counties Without Trip Data}

Eleven counties in the Piedmont/Triad region did not provide any trip information. A statistical method is applied to estimate a number of trips to the UNC/Duke medical areas. Using available passenger travel data of eight counties (Alamance, Davidson, Forsyth, Guilford, Randolph, Rockingham, Rowan, and Watauga), the gravity model was estimated.

(4) $\log ($ Annual passengers/Population $)=6.134-1.586 \times \log \left(\right.$ time $\left.^{2}\right)$

$$
\text { (0.74) (-1.70) }
$$

$$
\mathrm{R}^{2}=0.32
$$

(t-statistics)

The estimated model has an expected positive intercept and a negative coefficient on the travel time variable. Although an R-squared value of 0.32 seems a poor fit, with a small sample and an extremely simple model it may be considered satisfactory for rough prediction purposes. The estimated coefficient of the travel time variable is significant at a $10 \%$ level (the critical value is 1.440 with six degrees of freedom) on the one-sided test (however, insignificant at a $5 \%$ level with a critical value of 1.943). Then, the model is used to estimate annual numbers of passengers to the UNC/Duke medical areas, presented in Table 4. These estimates are reasonably within range of the numbers of passengers for distant counties that have passenger data (four passengers from Rowan County and 18 passengers from Watauga County). 
Non-Emergency Human Transport Services

Table 4: Passenger and Cost Saving Estimates for Nonparticipating Eleven Piedmont Counties

\begin{tabular}{|l|c|c|c|c|c|}
\hline & $\begin{array}{c}\text { Annual } \\
\text { Number of } \\
\text { Ambulant } \\
\text { Passengers }\end{array}$ & $\begin{array}{c}\text { Unit Travel } \\
\text { Cost to UNC } \\
\text { Medical Area }\end{array}$ & $\begin{array}{c}\text { Unit Travel } \\
\text { Cost to the } \\
\text { Nearest PART } \\
\text { Connections Stop }\end{array}$ & $\begin{array}{c}\text { Unit Cost } \\
\text { Saving of } \\
\text { Using PART } \\
\text { Connections }\end{array}$ & $\begin{array}{c}\text { Annual } \\
\text { Gross } \\
\text { Operating } \\
\text { Cost Saving }\end{array}$ \\
\hline Alexander & 2.1 & $\$ 103.04$ & $\$ 44.46$ & $\$ 14.13$ & $\$ 30$ \\
\hline Alleghany & 0.5 & $\$ 132.71$ & $\$ 59.22$ & $\$ 14.28$ & $\$ 7$ \\
\hline Ashe & 0.6 & $\$ 211.80$ & $\$ 111.36$ & $-\$ 10.92$ & $-\$ 6$ \\
\hline Caldwell & 2.8 & $\$ 335.98$ & $\$ 172.61$ & $-\$ 9.25$ & $-\$ 26$ \\
\hline Catawba & 8.2 & $\$ 344.56$ & $\$ 157.53$ & $\$ 29.49$ & $\$ 241$ \\
\hline Davie & 6.9 & $\$ 145.43$ & $\$ 34.35$ & $\$ 76.73$ & $\$ 527$ \\
\hline Iredell & 14.5 & $\$ 135.55$ & $\$ 44.96$ & $\$ 45.62$ & $\$ 661$ \\
\hline Stokes & 4.4 & $\$ 153.65$ & $\$ 48.28$ & $\$ 57.09$ & $\$ 253$ \\
\hline Surry & 8.5 & $\$ 162.58$ & $\$ 47.11$ & $\$ 68.36$ & $\$ 581$ \\
\hline Wilkes & 3.9 & $\$ 145.43$ & $\$ 58.06$ & $\$ 29.30$ & $\$ 114$ \\
\hline Yadkin & 6.5 & $\$ 147.07$ & $\$ 34.93$ & $\$ 77.22$ & $\$ 503$ \\
\hline
\end{tabular}

The model clearly illustrates that most trip demand comes from the central counties of the Piedmont/Triad region (Davie, Yadkin, Stokes, and Surry) and populated counties (Iredell and Catawba). Very few trips are expected for western Piedmont/Triad counties (Alleghany, Ashe, Wilkes, Caldwell, and Alexander) due to their low population and long travel time.

The same procedure is applied to compute unit travel cost estimates to the UNC/Duke medical areas, unit travel cost estimates to the nearest PART Connections stop, and unit cost saving and annual gross operating cost saving estimates of using PART Connections for the 11 counties. Because all of these counties are located in the western side of the Piedmont/Triad region, the nearest PART Connections stop is the one in Winston-Salem for all counties. Ashe and Caldwell counties, adjacent to Watauga County, are located close to the far western part of the Piedmont/Triad region and will be the only counties without any cost saving by using PART Connections. This holds true for the same reason in Watauga County, which also may not have any cost saving.

Therefore, the four currently participating counties could save $\$ 136,816$ annually, while the other 15 counties could save $\$ 9,636$ annually. In total, PART Connections could potentially save $\$ 146,452$ annually for 18 counties in the Piedmont/Triad region and Alamance County.

\section{Cost-Effectiveness of PART Connections}

Net Operating Cost Saving of Using PART Connections. The costs of operating PART Connections include driver, fuel, and vehicle maintenance. To cover its daily operating expense of $\$ 360$, PART charges fixed fees to the two major participating systems; Guilford County with a maximum charge of $\$ 220$ for guaranteeing four daily passengers, and Alamance County with a maximum charge of $\$ 140$ for guaranteeing six daily passengers. After paying fees to PART for the service, the county systems still have significant cost savings by using PART Connections, presented in Table 5. Annually, the Guilford County system will save \$24,271, while the Alamance County 
system will save $\$ 4,645$. The four county systems will save $\$ 43,216$ annually, after paying for the PART Connections service.

Table 5: Net Operating Cost Saving of PART Connections for Participating Counties

\begin{tabular}{|l|c|c|c|c|}
\hline & Guilford & Alamance & $\begin{array}{c}\text { Davidson } \& \\
\text { Forsyth }\end{array}$ & Total \\
\hline Gross Operating Cost Saving & $\$ 81,471$ & $\$ 41,045$ & $\$ 14,300$ & $\$ 136,816$ \\
\hline Payment to PART & $\$ 57,200$ & $\$ 36,400$ & ---- & $\$ 93,600$ \\
\hline Net Operating Cost Saving & $\$ 24,271$ & $\$ 4,645$ & $\$ 14,300$ & $\$ 43,216$ \\
\hline
\end{tabular}

\section{Net Operating Cost Saving of the Operation}

Currently, the daily operation cost of the PART Connections service ranges between $\$ 360$ and $\$ 400$, depending on hours of service and mileage. This daily cost includes operating expenses of drivers, fuel, and vehicle rent from the Winston-Salem Transit System. Using the median cost of \$380, PART Connections will cost PART \$98,800 annually, with 260 days of operation per year. Because PART is operating PART Connections on a cost-share basis with participating counties, this number is not far from fixed fees charged to the two counties (Guilford and Alamance). Deducting actual costs of operating PART Connections, the net saving by four counties will be $\$ 38,016$ annually $(\$ 136,816-\$ 98,800)$.

\section{Resource Share Allocated to Provide Services to the UNC/Duke Medical Areas}

Table 6 shows percentages of the number of passengers transported to the UNC/Duke medical areas, compared to the total number of passengers in selected counties. Guilford and Randolph counties have a very small fraction of passengers going to the UNC/Duke medical areas $(0.6 \%$ and $0.3 \%)$. These counties might allocate significantly higher proportions of operating expenses on the service to the UNC/Duke medical areas if each county had to provide it individually ( $3.1 \%$ and $6.3 \%)$. This indicates that these counties might be devoting more than a proportional amount of expenses for the out-of-county transport services. Furthermore, trips to UNC/Duke medical areas could take a noticeable share of service hours in these counties $(2.5 \%$ and $4.8 \%)$.

Table 6: Percentage of Passengers and Operating Expenses Spent on Transportation Service to the UNC/Duke Medical Areas

\begin{tabular}{|l|c|c|c|}
\hline & Guilford & Alamance & Randolph \\
\hline Total Passengers & 240,060 & 74,174 & 81,628 \\
\hline Total Passengers to UNC-CH \& Duke & 1355 & 4199 & 266 \\
\hline Percentage & $0.6 \%$ & $5.7 \%$ & $0.3 \%$ \\
\hline \hline Total Operating Expense & $\$ 2,604,561$ & $\$ 855,987$ & $\$ 429,206$ \\
\hline Median Total Cost for UNC-CH \& Duke Trips & $\$ 81,471$ & $\$ 41,045$ & $\$ 27,013$ \\
\hline Percentage & $3.1 \%$ & $4.8 \%$ & $6.3 \%$ \\
\hline Total Service Hours in System & 93,546 & 47,628 & 22,100 \\
\hline Total Service Hour for UNC-CH \& Duke Trips & 2,375 & 2,063 & 1,051 \\
\hline Percentage & $2.5 \%$ & $4.3 \%$ & $4.8 \%$ \\
\hline
\end{tabular}

Note: All other counties have less than $1 \%$. 


\section{Effective Use of Saved Resources}

Utilizing PART Connections would release some transportation resources of the participating county, such as drivers and vehicles. The county could use the saved resources to provide more intracounty transportation services to its residents, rather than saving the costs of operation. To estimate cost saving, it was assumed that each county makes two round trips to the nearest PART Connections stop. Between the two round trips, the county could provide transportation services within the county.

Table 7 shows estimated numbers of additional passengers each county could serve annually if the county could use the saved resources from the use of PART Connections. These estimates are based on the assumption that each system will maintain the same average service hours per passenger for additional passenger trips. Both Guilford County and Alamance County could serve significant numbers of passengers, while the most western counties can serve few additional passengers. In sum, these 18 counties in the Piedmont/Triad region and Alamance County could provide intracounty transportation services to 12,105 additional passengers annually by using the saved resources if they use PART Connections services.

Table 7: Number of Additional Passengers Served Within County

\begin{tabular}{|l|c|c|c|c|}
\hline & Guilford & Alamance & Forsyth & Davidson \\
\hline Time Savings (hours) & 2,375 & 2,063 & 352 & 3 \\
\hline Additional Passengers & 6,094 & 3,212 & 903 & 10 \\
\hline & Randolph & Rockingham & Rowan & Watauga \\
\hline Time Savings (hours) & 377 & 46 & 8 & 4 \\
\hline Additional Passengers & 1,394 & 99 & 19 & 74 \\
\hline & Alexander & Alleghany & Ashe & Caldwell \\
\hline Time Savings (hours) & 3.3 & 0.5 & 0.0 & 1.9 \\
\hline Additional Passengers & 5 & 1 & 0 & 6 \\
\hline & Davie & Stokes & Surry & Yadkin \\
\hline Time Savings (hours) & 20.4 & 9.5 & 23.5 & 19.8 \\
\hline Additional Passengers & 52 & 24 & 60 & 51 \\
\hline & Catawba & Iredell & Wilkes & \\
\hline Time Savings (hours) & 11.7 & 33.8 & 6.3 & \\
\hline Additional Passengers & 20 & 74 & 7 & \\
\hline
\end{tabular}

\section{CONCLUSION}

In the Piedmont/Triad region of North Carolina, the regional transportation agency began on April 5, 2004, to provide two daily transportation services between the Piedmont/Triad region and the UNC/ Duke medical areas. For the first nine-month period (April to December 2004), 4,232 passengers used PART Connections from four eastern counties in the region. On average, 22 passengers per day took the service to the UNC/Duke medical areas. If these four counties provided transportation services to the UNC/Duke medical areas separately, it could cost $\$ 136,816$ annually in total. Taking into account PART Connections operating expenses, PART Connections will provide a net saving of 
$\$ 38,016$ annually on the entire operation of the service. The savings come from coordinating trips and sharing rides to the same destination outside of their counties, which reduce the number of trips from four to one. The four participating counties could use the saved resources to provide more transportation services within each county. It is estimated that the four counties could provide a total of more than 10,000 additional intracounty passenger trips annually by using the saved resources from PART Connections.

A total of 12 local community transportation providers in the Piedmont/Triad region which are currently not participating in PART Connections could benefit from the service, too. They could save a modest $\$ 9,636$ annually by using PART Connections. The main reason for the small potential saving for the western Piedmont/Triad counties is a long travel distance between them and the nearest PART Connections stop in Winston-Salem. Because Winston-Salem is close to the midpoint of the entire trip to the UNC/Duke medical areas, with two round trips each time to the Winston-Salem PART Connections stop, these systems will not save much in driving distance or service time.

There are two scheduling procedures which will increase the cost savings of these counties. First, these counties already provide regular or periodic transportation services to the Baptist Hospital in Winston-Salem. A county can coordinate a trip to the UNC/Duke medical areas with a trip to the Baptist Hospital, and save one round trip to the PART Connections stop in Winston-Salem. The second cost-saving scheduling procedure is to coordinate trips to Winston-Salem among counties along the same highway. With cost share, these systems can save trip costs to Winston-Salem and benefit from more cost saving from PART Connections.

Alternatively, PART Connections can be extended to the Western Piedmont/Triad region. An extension should run in five western counties in the Piedmont/Triad region, and would provide a short access point to five additional further-western Piedmont/Triad counties. The extension should run through Winston-Salem, and continue its service to the UNC/Duke medical areas, so it can be combined with the large number of passengers to the Baptist Hospital in Winston-Salem.

\section{References}

Burkhardt, J. "Successful Coordinated Transportation Services in Rural Communities." Transportation Research Record 1903, (2005): 54-64.

Burkhardt, J.E., D. Koffman, and G. Murray. "Economic Benefits of Coordinating Human Service Transportation and Transit Services." (TCRP Report 91). Transportation Research Board of the National Academies, Washington, D.C., 2003.

Burkhardt, J.E., C. Nelson, and G. Murray. "Toolkit for Rural Community Coordinated Transportation Services." (TCRP Report 101). Transportation Research Board of the National Academies, Washington, D.C., 2004.

Cook, T.J. "North Carolina Department of Transportation Research Project 2002-11: Regionalizing Public Transportation Services." North Carolina State University: Institute for Transportation Research and Education, 2002.

Hawley, P., G. Worley, K. Angel, B. Smith, P. Stewart, R. Clayton, R. Boyd, S. Rhine, R. Keeney, M. Lovett, V. Brown, and D. Willis. "Cross County Transit Coordination Guidelines - Out-ofCounty Non-Emergency Medical Transportation." Public Transportation Division, North Carolina Department of Transportation, 2003.

Hegland, G., J. Miller, J. Mielke, and J. Hough. "Enhancing Passenger Mobility Services in North Dakota through Increased Coordination." Department Publication 160, Upper Great Plains Transportation Institute, North Dakota State University, 2004. 
Non-Emergency Human Transport Services

House Committee on Education and the Workforce. Joint Congress Hearing Outlines Benefits of Coordinating Human Services Transportation. Press Release, May 1, 2003. Retrieved October 2003 from http://www house.gov/ed_workforce/press/press 108/05may/ transpohrg050103 htm.

MAPQUEST. (2005). http://www mapquest.com.

McGrane, J., W. Grenney, and C. Johnson. "Survey of Implementation Strategies by Rural Paratransit Agencies Using Low-Cost Software." Mountain-Plains Consortium Report 04-161, Upper Great Plains Transportation Institute, North Dakota State University, 2004.

Murray, G., C. Chambers, R. Byrd, L. Collier, D. Curry, and C. Goodrich. "Using Public Transportation to Reduce the Economic, Social and Human Costs of Personal Mobility." (TCRP Report 49). Transportation Research Board of the National Academies, Washington, D.C., 1999.

North Carolina Department of Transportation, Operating and Financial Statistic Report, 2005.

North Carolina Department of Transportation, Public Transportation Today in North Carolina, 2003. Retrieved October 2003 from http://www ncdot.org/transit/transitnet/PublicInfo/ TransitToday. html.

Piedmont Authority for Regional Transportation, Regional Human Services Out-of-County Transportation Coordination Program, 2002. Retrieved October 2003 from http://www.partnc.org/ PART_connections-Brief htm.

Piedmont Authority for Regional Transportation. Regional Human Services Out-of-County Transportation Coordination Program Proposal, 2002. Retrieved October 2003 from http://www. partnc.org/PART_connections-Abstract.htm.

Rhoney, C. and J. Pratt. "Developing a State Regional Non-Emergency Medical Transportation Model (Pilot)." Proceeding of the National Conference on Undergraduate Research, Lexington, KY, 2001.

Rhoney, C., J. Pratt, R. Yearout, L. Nelms, S. King, and C. Singleton. “Adopting a Terrain Constrained Transshipment Model to Optimize State Regional Non-Emergency Medical Transportation Requirements." Proceeding of the 6th Annual International Conference on Industrial Engineering - Theory, Applications, and Practice, San Francisco, CA, 2001.

Rubel, T., P. Psilos, P. Kalomiris, and J. Mueller. "Improving Public Transportation Services Through Effective Statewide Coordination.” National Governors Association, 2002.

White House. Human Service Transportation Coordination, 2004. Retrieved June 2004 from http:// www.whitehouse.gov/news/releases/2004/02/20040224-9.html.

\section{Acknowledgements}

This research was supported in part by the Transportation Institute, Urban Transit Institute of North Carolina A\&T State University. The authors wish to thank Mr. Scott Rhine and Ms. Amanda Hayes of PART for providing PART Connections operational data and their suggestions in the preparation of the questionnaire and report, and Ms. Pamela Hawley of NCDOT for providing OPSTATS data. The editor of the journal and anonymous referees provided valuable suggestions and helped to improve the paper greatly. 
Ryoichi Sakano is associate professor in the Department of Economics and Transportation/Logistics at North Carolina A\&T State University. He received his Ph.D. in economics from the University of Alabama and has published research in the areas of efficiency and productivity of public transits, travel behavior, and income distribution in various transportation and economics journals.

Julian Benjamin is a professor in the Department of Economics and Transportation/Logistics at North Carolina A\& T State University. He received his Ph.D. from the Department of Civil Engineering at the State University of New York at Buffalo. His research has focused on special transportation, travel demand analysis and cost optimization of supply chains. He has many publications in these areas with several that look at the application of demand analysis to planning services in a special transportation agency. 